\title{
Forequarter Amputation
}

\section{Constantine P. Karakousis, MD, PhD, FACS and John L. Butsch, MD, FACS}

Buffalo General Hospital, Buffalo, NY

\begin{abstract}
Forequarter amputation is performed for tumors invading the brachial plexus in the axilla. The technique of anterior and posterior approach is described. The deltoid fasciocutaneous flap is described which can provide coverage of a chest wall defect when needed.
\end{abstract}

Electronic supplementary material The online version of this article (doi:10.1245/s10434-010-1439-8) contains supplementary material, which is available to authorized users.

(C) Society of Surgical Oncology 2010

First Received: 7 January 2010;

Published Online: 24 December 2010

C. P. Karakousis, MD, PhD, FACS

e-mail: Ckarakousis@kaleidahealth.org 